\title{
Limits of weak light phase measurements for inter-spacecraft laser interferometry and coherent optical communications (Conference Presentation)
}

Daniel A. Shaddock (/profile/Daniel.Shaddock-37551).

Author Affiliations + ().

Proceedings Volume 11297, Complex Light and Optical Forces XIV; (/conference-proceedings-ofspie/11297.toc) 112970S (2020) https://doi.org/10.1117/12.2548399 (https://doi.org/10.1117/12.2548399) Event: SPIE OPTO (/conference-proceedings-of-spie/browse/SPIE-Photonics-West/SPIE-OPTO/2020), 2020, San Francisco, California, United States

ARTICLE CITED BY

\begin{abstract}
Measuring the phase of low power optical signals is important for space-based gravitational wave detection, geodesy measurements and free-space optical communications. Phase measurements are required in heterodyne interferometry and are commonly implemented by phasemeters based on In-phase and Quadrature demodulation or phase-locked loops. Laser frequency noise and quantum noise set competing requirements on phasemeter design. Poor optimisation of the phase measurement system can lead to a breakdown of the measurement due to cycle slipping, an ungraceful degradation of phase measurement performance. This talk will explore the fundamental limitations of weak light phase measurements, highlight design considerations for such a phase measurement system and present recent experimental results for weak light phase measurements. These findings may expand the design parameter space for future intersatellite laser interferometry and communication instruments.
\end{abstract}

\section{Conference Presentation}

\section{$\checkmark$ Show Transcript}

( ) (2020) COPYRIGHT Society of Photo-Optical Instrumentation Engineers (SPIE). Downloading of the abstract is permitted for personal use only.

\section{Citation Download Citation -}

Daniel A. Shaddock (/profile/Daniel.Shaddock-37551) "Limits of weak light phase measurements for interspacecraft laser interferometry and coherent optical communications (Conference Presentation)", Proc.

PROCEEDINGS

PRESENTATION

WATCH

PRESENTATION

SAVE TO MY LIBRARY GET CITATION

$<$ Previous Article (/conferenceproceedings-ofspie/11297/112970O/GRIN-lens--a-new-

element-for-complex-vectorialbeam/10.1117/12.2545557.full) | Next Article (/conference-proceedings-ofspie/11297/112970T/Higher-order-Besselbeams-integrated-with-time-HOBBIT-fordynamic/10.1117/12.2551312.full) >

Advertisement 
Free space optical communications

(/search?

keyword=Free space optical communications).

Free space optics (/search?

keyword=Free space optics).

Geodesy_(search?keyword=Geodesy.).

Heterodyning_/search?

keyword=Heterodyning).

Show All Keywords

RELATED CONTENT

Improved measurement of beacon light angle deviation based on a...

(Iconference-proceedings-of-

spie/11341/113410D/Improved-

measurement-of-beacon-light-angle-

deviation-based-on-

a/10.1117/12.2540987.full)

Proceedings of SPIE (December 18 2019)

Full field heterodyne dynamic interferometry based on hertz level low... (/conference-proceedings-ofspie/10329/1032905/Full-fieldheterodyne-dynamic-interferometry= based-on-hertz-level-

low/10.1117/12.2270138.full).

Proceedings of SPIE (June 26 2017)

New method for measuring the thickness and shape of a...

(Iconference-proceedings-ofspie/2861/0000/New-method-formeasuring-the-thickness-and-shape-ofa/10.1117/12.245168.full)

Proceedings of SPIE (July 19 1996)

Heterodyne Interferometry With A Frequency Modulation Of A Laser Diode (/conference-proceedings-ofspie/813/0000/Heterodyne-

Interferometry-With-A-Frequency-

Modulation-Of-A-Laser-

Diode/10.1117/12.967139.full)

Proceedings of SPIE (January 01 1987)

Two-Wavelength Laser Interferometry. Using Super-Heterodyne Detection (Iconference-proceedings-ofspie/813/0000/Two-Wavelength-LaserInterferometry-Using-SuperHeterodyne-

Detection/10.1117/12.967129.full).

Proceedings of SPIE (January 01 1987)

The development of 622 Mbits s free space laser communication... (Iconference-proceedings-ofspie/5644/0000/The-development-of622-Mbits-s-free-space-lasercommunication/10.1117/12.572691.full). Proceedings of SPIE (January 17 2005) 
Numerical investigation of effect of dynamic range and nonlinearity of...

(/conference-proceedings-of-

spie/1332/0000/Numerical-investigation-

of-effect-of-dynamic-range-and-

nonlinearity-of/10.1117/12.51071.full).

Proceedings of SPIE (January 01 1991)

Subscribe to Digital Library. (/subscribe-page)

! Receive Erratum Email Alert () 